2002

\title{
Effects of Nonequilibrium Atmospheric Pressure Plasmas on the Heterotrophic Pathways of Bacteria and on their Cell Morphology
}

Mounir Laroussi

Old Dominion University, mlarouss@odu.edu

J. Paul Richardson

Old Dominion University

Fred C. Dobbs

Old Dominion University, fdobbs@odu.edu

Follow this and additional works at: https://digitalcommons.odu.edu/oeas_fac_pubs

Part of the Bacteriology Commons, and the Biological and Chemical Physics Commons

\section{Repository Citation}

Laroussi, Mounir; Richardson, J. Paul; and Dobbs, Fred C., "Effects of Nonequilibrium Atmospheric Pressure Plasmas on the Heterotrophic Pathways of Bacteria and on their Cell Morphology" (2002). OEAS Faculty Publications. 5.

https://digitalcommons.odu.edu/oeas_fac_pubs/5

\section{Original Publication Citation}

Laroussi, M., Richardson, J.P., \& Dobbs, F.C. (2002). Effects of nonequilibrium atmospheric pressure plasmas on the heterotrophic pathways of bacteria and on their cell morphology. Applied Physics Letters, 81(4), 772-774. doi: 10.1063/1.1494863 


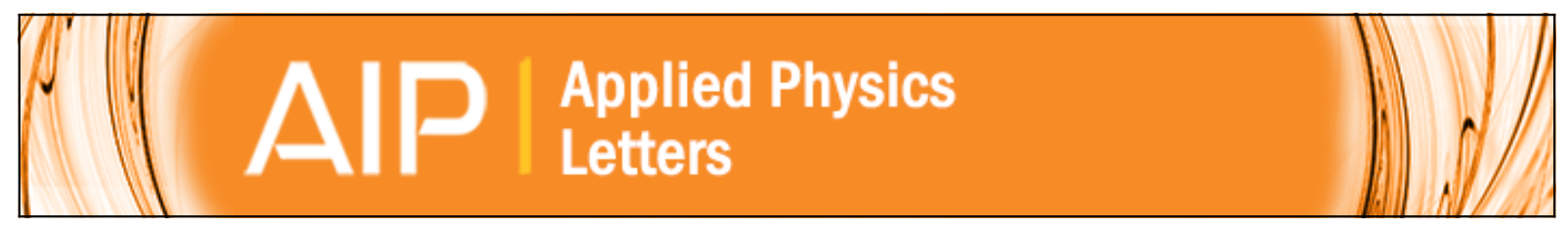

\section{Effects of nonequilibrium atmospheric pressure plasmas on the heterotrophic pathways of bacteria and on their cell morphology}

Mounir Laroussi, J. Paul Richardson, and Fred C. Dobbs

Citation: Applied Physics Letters 81, 772 (2002); doi: 10.1063/1.1494863

View online: http://dx.doi.org/10.1063/1.1494863

View Table of Contents: http://scitation.aip.org/content/aip/journal/apl/81/4?ver=pdfcov

Published by the AIP Publishing

\section{Articles you may be interested in}

Effects of air transient spark discharge and helium plasma jet on water, bacteria, cells, and biomolecules Biointerphases 10, 029515 (2015); 10.1116/1.4919559

Non-thermal plasma mills bacteria: Scanning electron microscopy observations Appl. Phys. Lett. 106, 053703 (2015); 10.1063/1.4907624

The effect of nanofiber based filter morphology on bacteria deactivation during water filtration AIP Conf. Proc. 1526, 316 (2013); 10.1063/1.4802626

Highly effective fungal inactivation in $\mathrm{He}+\mathrm{O} 2$ atmospheric-pressure nonequilibrium plasmas Phys. Plasmas 17, 123502 (2010); 10.1063/1.3526678

Influence of oxygen in atmospheric-pressure argon plasma jet on sterilization of Bacillus atrophaeous spores Phys. Plasmas 14, 093504 (2007); 10.1063/1.2773705

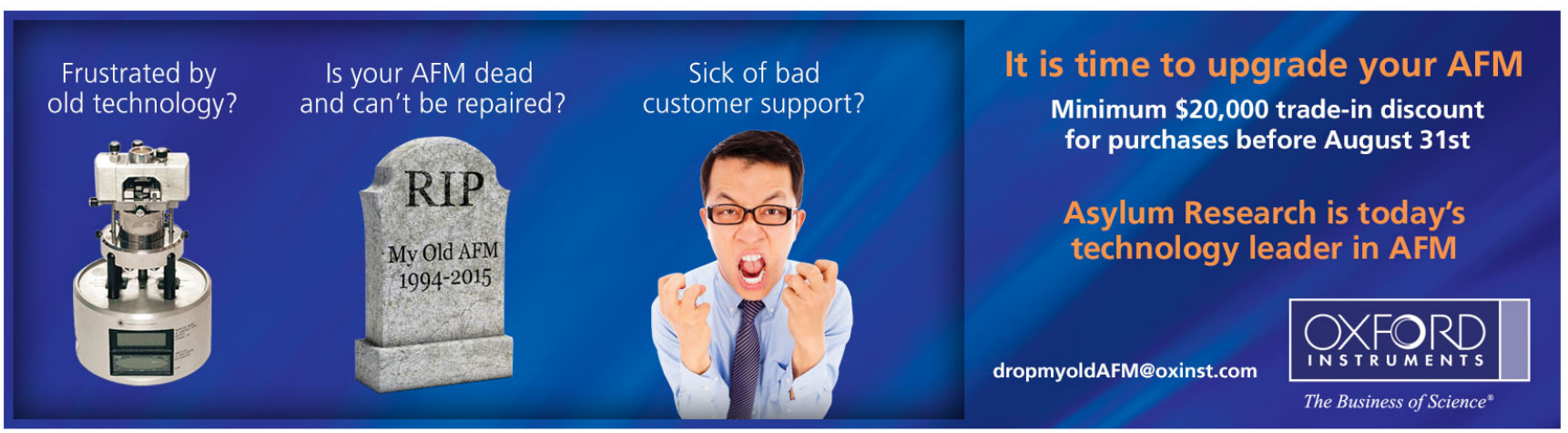




\title{
Effects of nonequilibrium atmospheric pressure plasmas on the heterotrophic pathways of bacteria and on their cell morphology
}

\author{
Mounir Laroussi, ${ }^{\text {a) }}$ J. Paul Richardson, ${ }^{\text {b) }}$ and Fred C. Dobbs ${ }^{\text {b) }}$ \\ Old Dominion University, Applied Research Center, 12050 Jefferson Ave., Newport News, Virginia 23606
}

(Received 22 March 2002; accepted for publication 29 May 2002)

\begin{abstract}
To date, most research on the interaction of nonequilibrium, atmospheric pressure plasma discharges with bacteria has concentrated on the germicidal effects. Therefore, published results deal mainly with killing efficacy and little attention is given to physical mechanisms and biochemical pathways and their potential alterations when cells of microorganisms are exposed to the plasma. In this letter, an attempt to investigate the effects of plasma exposure on the biochemical pathways of bacteria is presented. In addition, using electron microscopy, we investigate if any gross morphological changes take place when cells are exposed to a lethal dose of plasma. We are testing the hypothesis that disruption of the cell membrane, sometimes to the point of cell lysis, is the mechanism whereby plasma kills cells. (C) 2002 American Institute of Physics. [DOI: 10.1063/1.1494863]
\end{abstract}

Recently, the ability to generate relatively large volumes of nonthermal gaseous discharges at atmospheric pressure allowed the emergence of exciting applications..$^{1-4}$ Among these are the biological applications of atmospheric pressure glow discharges, ${ }^{4-7}$ which brought together plasma physicists and microbiologists. In addition to the basic scientific knowledge that such research is bound to contribute, plasmas are being considered as a potential means for the sterilization of reusable medical tools and for the decontamination of biological and chemical warfare agents. ${ }^{4,5}$ The ability to generate nonthermal plasma discharges at pressures at or near 1 atm makes the decontamination process practical and inexpensive. In addition, the fact that the gas temperature in such discharges remains relatively low makes their use suitable for applications where medium preservation is desired. Unfortunately, the drive to develop a practical means of decontamination has led researchers to concentrate on the germicidal effects of plasmas with little attention given to their effects on fundamental physical and biological processes. Here we present an attempt to elucidate the effects of plasmas on the biochemical pathways of Escherichia coli. In order to carry out such a study, cells of $E$. coli were exposed to a sublethal dose of cold plasma then seeded into various carbon substrates to evaluate any changes in substrate utilization relative to control cells. These changes are presumed indicative of plasma-induced changes in cell function. In addition, we used electron microscopy to investigate whether any gross morphological changes take place when cells of $E$. coli and Bacillus subtilis are exposed to a lethal dose of plasma. We are testing the hypothesis that disruption of the cell membrane is the mechanism whereby plasma kills cells. $^{7,8}$

The plasma used in our experiments was produced by a resistive barrier discharge (RBD). ${ }^{9}$ Figure 1 shows the gen-

a) Author to whom correspondence should be addressed; electronic mail: mlarouss@odu.edu

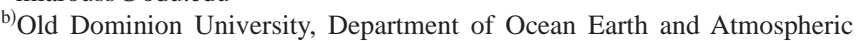
Sciences, 4600 Elkhorn Ave., Norfolk, VA 23529. eral configuration of the RBD. The plasma filled the gap (gap width $=4.5 \mathrm{~cm}$ ) between two planar copper disk electrodes (diameter $=10 \mathrm{~cm}$ ), one of which was covered by a high resistivity material. The electrodes were directly energized by a high voltage transformer delivering a voltage with a rms value up to $16 \mathrm{kV}$ (at $60 \mathrm{~Hz}$ ). The electrodes were contained within an enclosure in which a gas mixture of $97 \%$ helium and $3 \%$ oxygen was introduced. After the gas mixture was introduced, the plasma was ignited and maintained simply by adjusting the voltage source to the desired magnitude.

The biochemical impacts of a cold plasma generated by RBD on Escherichia coli were addressed with sole carbon substrate utilization (SCSU) experiments, using Biolog (Hayward, CA) GN2 ${ }^{\text {TM }}$ 96-well microtiter plates. The purpose of the SCSU experiments was to determine if exposure to plasma alters the heterotrophic pathways of the bacteria. It is presumed that any changes in metabolism would be indicative of plasma-induced changes in cell function. The Biolog GN2 plate is comprised of a control well and 95 other wells, each containing a different carbon substrate. Color development of a redox dye present in each well indicates utilization of that particular substrate by the inoculated bacteria.

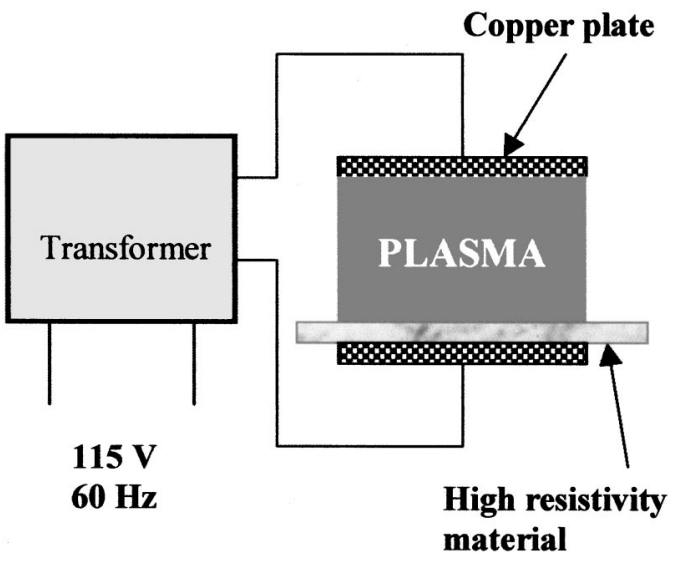

FIG. 1. Configuration of the resistive barrier discharge. 


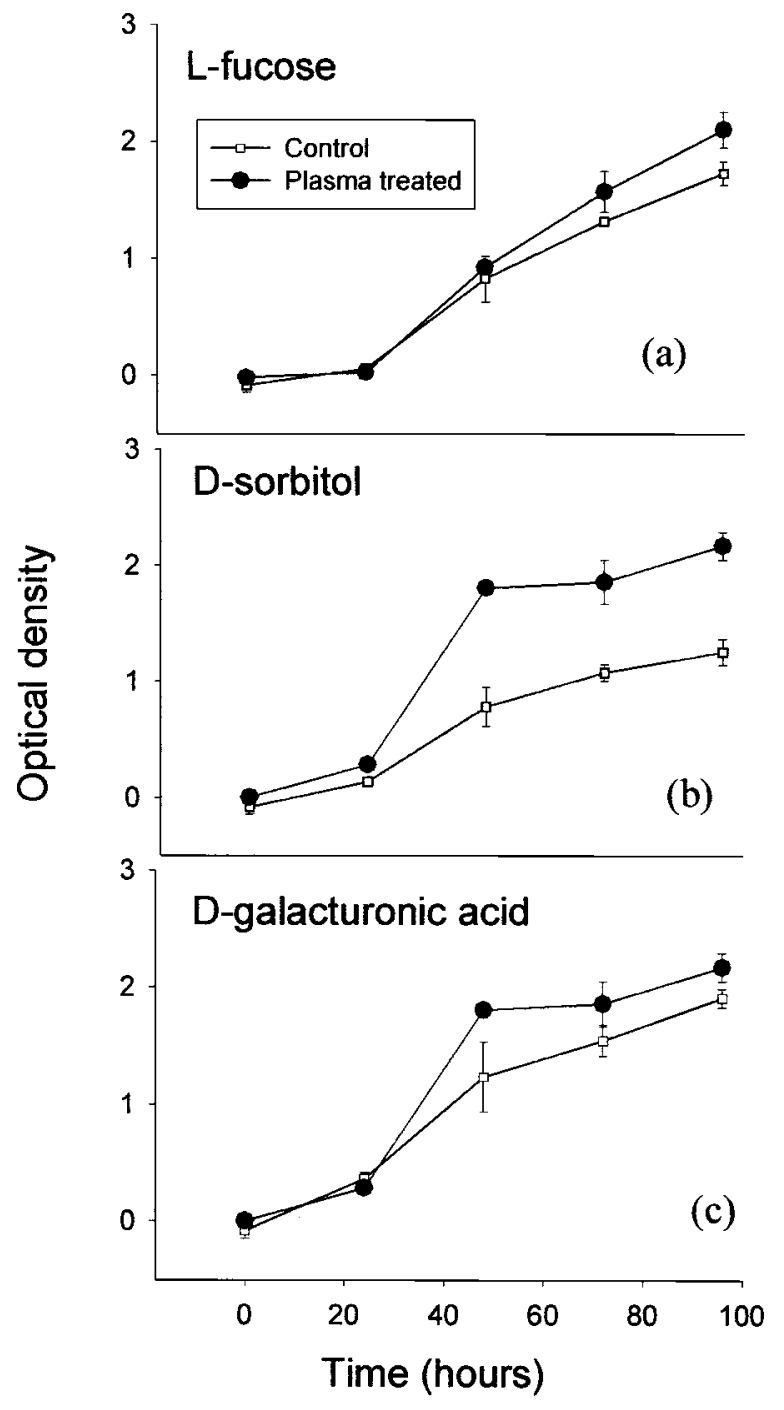

FIG. 2. Increased utilization of sole source carbon substrate by plasma treated E. coli cells. (a) 1-fucose, (b) d-sorbitol, (c) d-galacturonic acid.

The 95 substrates are dominated by amino acids, carbohydrates, and carboxylic acids. The extent and rate of color development for plasma treated cells and control cells were determined over five days at 24 hour intervals, by measuring the optical densities of each well with a microplate reader.

The optical densities (ODs) of the control wells were subtracted from the ODs of each of the 95 carbon substrates and an average well color development (AWCD) for each Biolog plate was calculated according to Garland and Mills. ${ }^{10}$ The AWCD was evaluated to determine whether an overall effect of the plasma treatment was observed. For the sublethal exposures administered in these experiments, no difference in AWCD between controls and plasma treated cells emerged. Next, the temporal pattern of color development for each carbon substrate was compared for the control cells and the plasma treated cells.

Although for most substrates no appreciable differences emerged, exposure to plasma was associated with significant changes in the utilization of some substrates. Figure 2 indicates an increased utilization (relative to the control cells) of several substrates (L-fucose, D-sorbitol, and D-galacturonic acid) by the plasma treated cells, and Fig. 3 indicates a de-
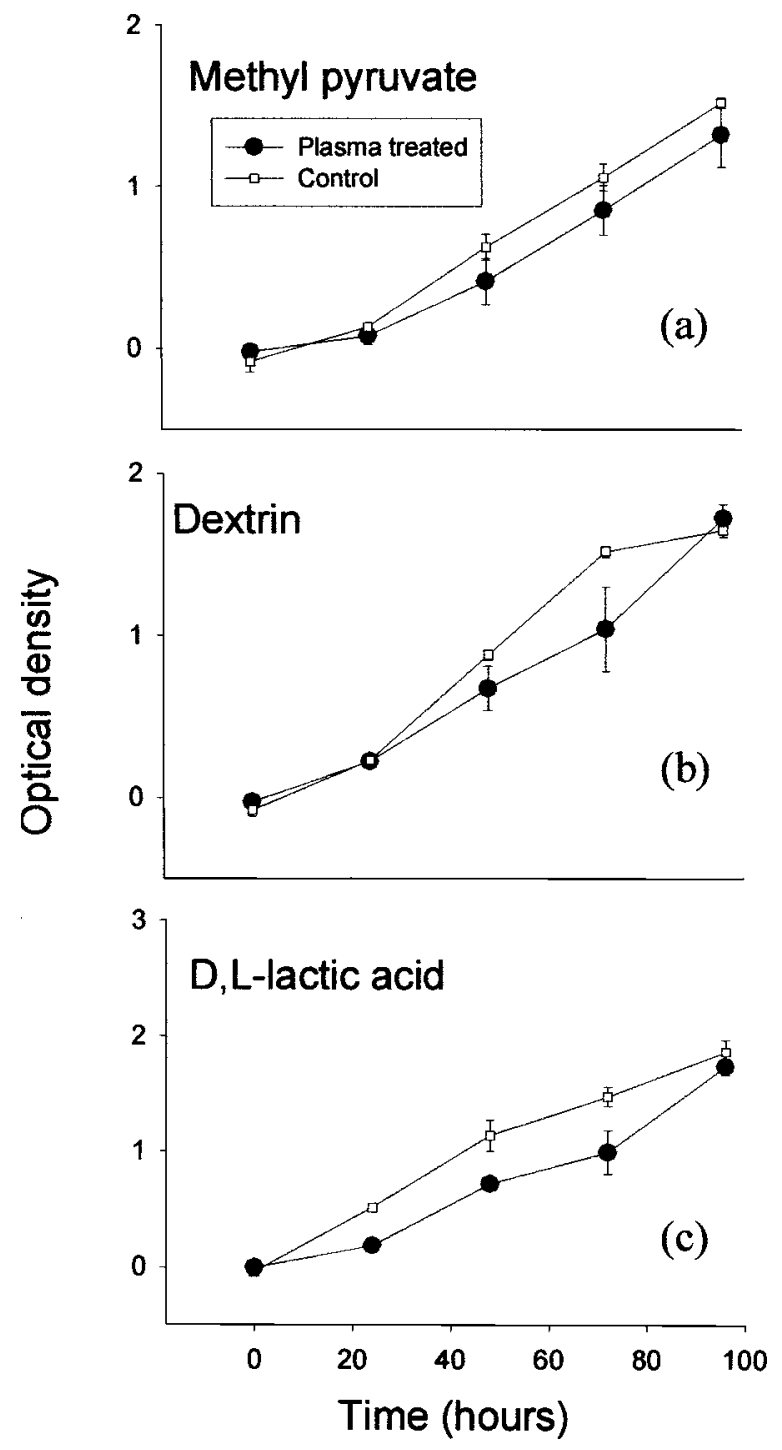

FIG. 3. Decreased utilization of sole source carbon substrates by plasma treated E. coli cells. (a) Methyl puryvate, (b) dextrin, (c) d,l-lactic acid.

creased utilization of other substrates (methyl pyruvate, dextrin, and D, L-lactic acid). These changes were presumed indicative of plasma-induced alterations in some aspects of cellular functions (possibly enzyme activity)

To investigate any effects of cold plasmas on the morphology of bacteria we used scanning electron microscopy to inspect cells for gross physical damage following exposure to lethal doses. Representative Gram-negative (E. Coli) and Gram-positive bacteria (B. subtilis) were concentrated on filters, then exposed to plasma and subsequently examined microscopically. Figure 4 shows that cells of E. coli were heavily damaged following exposure to the plasma, to the point where membrane integrity was largely lost and their cytoplasm was distributed in clumps on the filter. Figure 5, on the other hand, shows that cells of B. subtilis exhibited no morphological change relative to the control cells.

Mendis, Rosenberg, and Azam ${ }^{8}$ theoretically predicted such an outcome on the basis of a disequilibrium between the forces exerted by the outward electrostatic tension and the tensile strength of the membrane. Mendis and co-workers ${ }^{8}$ claim that since the membrane of Gramnegative bacteria is irregular in structure, the outward elec- 


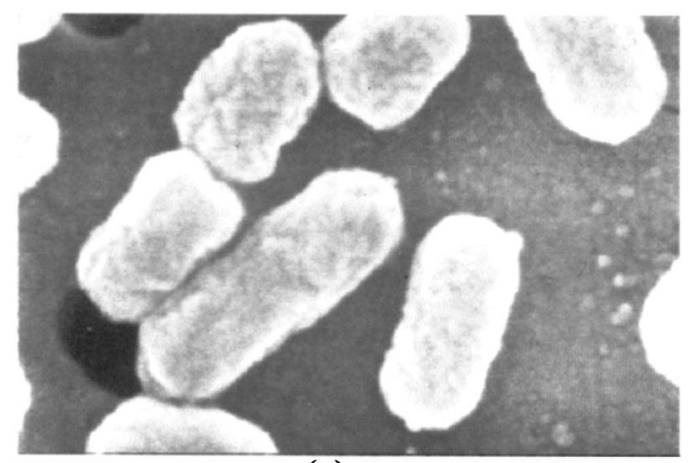

(a)

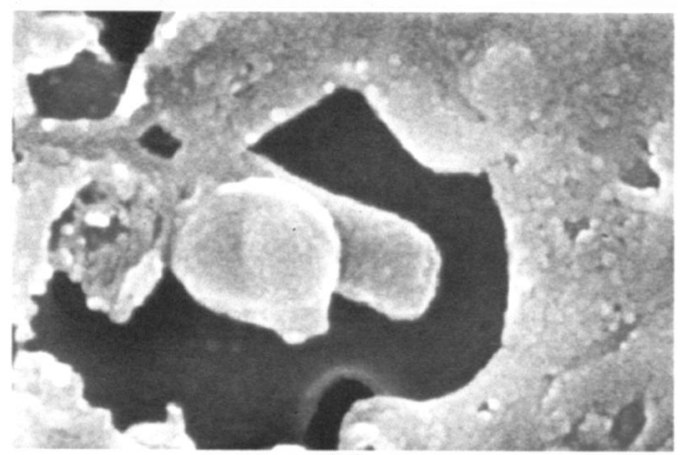

(b)

$300 \mathrm{~nm}$

FIG. 4. Scanning electron microscope micrographs of E. coli cells. (a) Control, (b) plasma treated.

trostatic tension (due to charge collection on the outer surface of the cells) is much higher than that in the case of Gram-positive bacteria, which exhibit a membrane having a smoother surface. This higher electrostatic tension can overcome the tensile strength of the membrane and induce its rupture.

This letter reports the effects of nonequilibrium atmospheric pressure plasma on heterotrophic pathways and cell morphology of bacteria. It shows that before cell destruction takes place, normal cell functioning can be altered by exposure to plasma. However, whether sublethal effects are reversible, cause irreversible damage (or mutation) to the cells, or ultimately lead to cellular death is unknown. In addition, the morphological effects of plasma exposure differed between the two species of bacteria tested. Membrane integrity of $E$. coli was severely compromised following exposure to plasma, but no apparent morphological effects were manifested on B. subtilis.

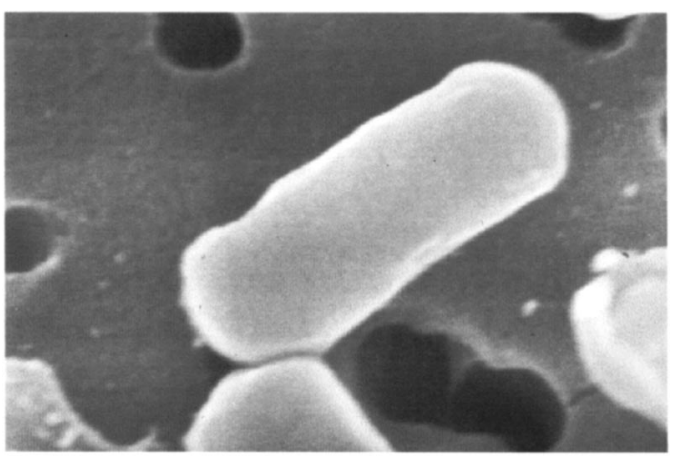

(a)

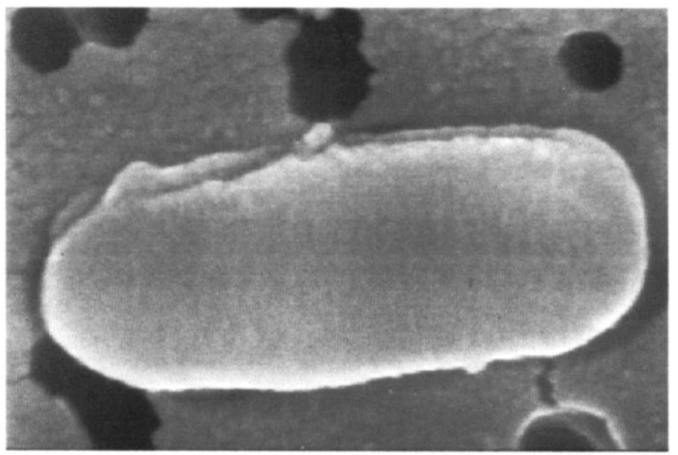

$300 \mathrm{~nm}$

FIG. 5. Scanning electron microscope micrographs of B. subtilis cells. (a) Control, (b) plasma treated.

This work was partly supported by AFOSR Grant No. F49620-00-1-0168. The electron microscopy work was done at the Electron Microscopy Laboratory within the Department of Biological Sciences of Old Dominion University.

${ }^{1}$ B. Eliasson and U. Kogelschatz, IEEE Trans. Plasma Sci. 19, 1063 (1991).

${ }^{2}$ A. Elhabachi and K. H. Schoenbach, Appl. Phys. Lett. 73, 885 (1998).

${ }^{3}$ M. Laroussi, Int. J. Infrared Millim. Waves 16, 2069 (1995).

${ }^{4}$ M. Laroussi, IEEE Trans. Plasma Sci. 24, 1188 (1996).

${ }^{5}$ H. W. Herman, I. Henins, J. Park, and G. S. Selwyn, Phys. Plasmas 6, 2284 (1999).

${ }^{6}$ N. M. Efremov, B. Yu Adamiak, V. I. Blochin, S. Ja Dadashev, K. I. Dimitriev, O. P. Gryaznova, and V. F. Jubashev, IEEE Trans. Plasma Sci. 28, 238 (2000).

${ }^{7}$ M. Laroussi, I. Alexeff, and W. Kang, IEEE Trans. Plasma Sci. 28, 184 (2000).

${ }^{8}$ D. A. Mendis, M. Rosenberg, and F. Azam, IEEE Trans. Plasma Sci. 28, 1304 (2000).

${ }^{9}$ M. Laroussi, I. Alexeff, J. P. Richardson, and F. F. Dyer, IEEE Trans. Plasma Sci. 30, 158 (2002).

${ }^{10}$ J. L. Garland and A. L. Mills, Appl. Environ. Microbiol. 57, 2351 (1991). 